\title{
Isolation of Intestinal Parasites of Public Health Importance from Cockroaches (Blattella germanica) in Jimma Town, Southwestern Ethiopia
}

\author{
Haji Hamu, ${ }^{1}$ Serkadis Debalke, ${ }^{1}$ Endalew Zemene, ${ }^{1}$ Belay Birlie, ${ }^{2}$ \\ Zeleke Mekonnen, ${ }^{1}$ and Delenasaw Yewhalaw ${ }^{3}$ \\ ${ }^{1}$ Department of Medical Laboratory Sciences and Pathology, College of Public Health and Medical Sciences, \\ Jimma University, Jimma, Ethiopia \\ ${ }^{2}$ Department of Statistics, College of Natural Sciences, Jimma University, Jimma, Ethiopia \\ ${ }^{3}$ Department of Biology, College of Natural Sciences, Jimma University, Jimma, Ethiopia
}

Correspondence should be addressed to Delenasaw Yewhalaw; delenasawye@yahoo.com

Received 5 August 2013; Accepted 9 November 2013; Published 4 February 2014

Academic Editor: Joseé F. Silveira

Copyright (C) 2014 Haji Hamu et al. This is an open access article distributed under the Creative Commons Attribution License, which permits unrestricted use, distribution, and reproduction in any medium, provided the original work is properly cited.

\begin{abstract}
Cockroaches are claimed to be mechanical transmitters of disease causing microorganisms such as intestinal parasites, bacteria, fungi, and viruses. This study assessed the potential of the German cockroach Blattella germanica in the mechanical transmission of intestinal parasites of public health importance. A total of 2010 cockroaches were collected from 404 households in Jimma Town, southwestern Ethiopia. All the collected cockroaches were identified to species as B. germanica. The contents of their gut and external body parts were examined for the presence of intestinal parasites. Overall, $152(75.6 \%)$ of the 210 batches were found to harbor at least one species of human intestinal parasite. Ascaris lumbricoides, Trichuris trichiura, Taenia spp, Strongyloideslike parasite, Entamoeba histolytica/dispar/moshkovski, Giardia duodenalis and Balantidium coli were detected from gut contents. Moreover, parasites were also isolated from the external surface in $22(10.95 \%)$ of the batches. There was significant difference in parasite carriage rate of the cockroaches among the study sites $(P=0.013)$. In conclusion, B. germanica was found to harbor intestinal parasites of public health importance. Hence, awareness on the potential role of cockroaches in the mechanical transmission of human intestinal parasites needs to be created. Moreover, further identification of the Strongyloides-like worm is required using molecular diagnostics.
\end{abstract}

\section{Introduction}

Cockroaches are distributed throughout the world and they are among the most notorious insects inhabiting apartments, food handling establishments, and health care facilities. Over 3500 species of cockroaches have been identified. Thirty of these species are more adapted to human habitation or synanthropic. Of these, Blattella germanica (German cockroach), Periplaneta americana (American cockroach), and $B$. orientalis (the Oriental cockroach) are considered the most common pests to humans [1-3].

Cockroaches have indiscriminate dietary habits. Moreover, adult cockroaches have the ability to survive without food for several weeks. They have the ability to breed all year long in suitable environmental conditions. These features of cockroaches, together with their nocturnal activity, probably make them widespread $[1,4]$.

Several evidences show that cockroaches are carriers of medically important parasites including helminths and protozoa [5-9]. For instance, a field survey carried out in 11 primary schools in Taiwan documented that $4 \%$ of the $P$. americana and $10 \%$ of B. germanica examined harbored cysts of Entamoeba histolytica/dispar/moshkovskii on their cuticle and/or in the digestive tract [10]. Besides parasites, several species of bacteria and fungi that can potentially cause human diseases have been isolated from cockroaches $[3,5,11]$. Such pathogenic microorganisms are isolated from cockroaches probably because cockroaches frequently feed on human 
feces. Apart from acting as mechanical carriers of microorganisms, cockroaches are the major sources of indoor allergens. Exposure and sensitization to cockroach allergen are associated with asthma-related health problems [12], the magnitude of which depends on race and socioeconomic status [13].

Intestinal parasites are relatively common among residents in Jimma Town [14]. Examination of soil around residential areas in the town also shows that these gastrointestinal parasites are very common [15], probably due to poor human excreta disposal mechanism. The warm and moist environmental condition of Jimma Town makes the area an ideal natural habitat for the inhabitation of cockroaches.

Despite the abundance of cockroaches in residential areas in Jimma Town and the high prevalence of intestinal parasites in this urban setting, to our knowledge, there is no documented data on the role of cockroaches as carriers of intestinal parasites in the study area. Lack of information on the role of cockroaches in carrying these human parasites is what initiated this study, which is aimed at isolating parasites of public health importance from cockroaches collected from residential houses. The findings of the study will shed light on the potential role of cockroaches in the mechanical transmission of intestinal parasites and help to design more efficient control intervention strategy for the control of synanthropic cockroaches.

\section{Materials and Methods}

2.1. Study Setting. The study was conducted in Jimma Town, southwestern Ethiopia, from February to March 2012.

The study area is located $335 \mathrm{kms}$ southwest of Addis Ababa, at an average altitude of 1,780 meters above sea level. The town has a climatic condition locally known as "Woynadega" (1,500-2,400 $\mathrm{m}$ above sea level). The town is generally characterized by a warm climate with a mean annual maximum temperature of $30^{\circ} \mathrm{C}$ and a mean annual minimum temperature of $14^{\circ} \mathrm{C}$.

The annual rainfall ranges from 1138 to $1690 \mathrm{~mm}$. The maximum precipitation occurs during the months of June to September, with minimum rainfall between December and January. Humid and hot climate makes the area conducive for cockroaches.

2.2. Cockroach Sampling, Identification, and Parasite Isolation. Two thousand and ten cockroaches were collected over a period of two months. The cockroaches were collected from 404 households selected from five of the 13 kebeles (the smallest administrative units in Ethiopia). The five kebeles were selected randomly. Indoor collection of cockroaches was carried out from selected households two months prior to the indoor residual spraying (IRS) operation for malaria control in the kebeles. Only adult cockroaches with an intact body were processed in the laboratory. The cockroaches were collected using empty jars coated with a thin film of vaseline baited with a piece of bread soaked in water. The collection jars were put at 19:00 hr and retrieved at 7:00 hr in the morning.
The trapped cockroach specimens were placed in labeled jars and transported to the Medical Parasitology Laboratory, Jimma University, for identification and further processing.

Morphological identification of the cockroaches was carried out using standard taxonomic keys [16]. Two hundred and ten batches of cockroaches (each batch with 10 cockroaches) were processed. Internal (gut) and external body surface contents of the cockroach specimens were processed as described elsewhere (3). Parasite species isolated from cockroaches' gut and external body surfaces were identified following Cheesbrough [17].

2.3. Data Analysis. In order to gain insight of the data, exploratory data analysis was performed. Cross-tabulation of the outcome presence of intestinal parasites and covariates (kebele and cockroach body part) was performed. In order to test whether the observed counts differ from the expected counts, a Chi-square test was employed.

\section{Results}

A total of 2,010 cockroaches (201 batches) were collected indoors from 404 households selected from five kebeles of Jimma Town, southwestern Ethiopia. All the collected cockroaches were identified to species level as B. germanica. Of the 201 batches of cockroaches screened, 152 (75.6\%) were found to harbor at least one intestinal parasite species. There was a significant difference $(P=0.013)$ in the prevalence of intestinal parasites recovered from the batches of cockroaches among different kebeles (Table 1). Moreover, there was a significant difference in helminths carriage of the cockroaches among kebeles $(P=0.032)$ and the difference in protozoa parasite carriage of cockroaches among kebeles was also highly significant $(P<0.001)$.

Parasites were identified from the internal contents (gut) of all the positive batches of the cockroaches. Of the 201 batches of cockroaches examined, 22 (10.9\%) and 152 (75.6\%) batches were found to harbor parasites on their external body surfaces and guts, respectively (Table 2 ).

With respect to the types of parasites isolated, overall, $40.3 \%$ (95\% CI: 33.52-47.08) of the batches harbored helminths only, $4.98 \%$ (95\% CI: $1.97-7.98$ ) of them had only protozoa, and the remaining 30.35\% (95\% CI: 23.99-36.70) had both helminths and protozoa.

Overall, seven species of medically important parasites were identified (Figure 1). The helminths include A. lumbricoides, T. trichiura, Taenia species, and an unidentified Strongyloides-like parasite. The protozoan parasites isolated were E. histolytica/dispar/moshkovskii, G. duodenalis, and B. coli. In this study, the most predominant parasite isolated was the suspected Strongyloides-like parasite.

\section{Discussion}

In this study, intestinal parasite species of medical importance were identified from the body surfaces and gut contents of the cockroaches. Accordingly, $75.6 \%$ of the batch of cockroach 
TABLE 1: Percentage of parasites isolated from populations of B. germanica by kebele in Jimma Town, southwestern Ethiopia, 2012.

\begin{tabular}{|c|c|c|c|c|}
\hline Kebele & Batch no. of cockroaches examined & Parasite isolated & $n(\%)$ & $95 \% \mathrm{CI}$ \\
\hline \multirow{3}{*}{ Bossa Addis } & \multirow[t]{3}{*}{ ( } & Helminths & $15(46.88)$ & $(29.58,64.17)$ \\
\hline & & Protozoa & $5(15.63)$ & $(3.04,28.20)$ \\
\hline & & Total & $17(53.13)$ & $(35.83,70.42)$ \\
\hline \multirow{3}{*}{ Ginjo } & \multirow{3}{*}{35} & Helminths & $26(74.29)$ & $(59.8,88.77)$ \\
\hline & & Protozoa & $8(22.86)$ & $(8.95,36.77)$ \\
\hline & & Total & $26(74.29)$ & $(59.8,88.77)$ \\
\hline \multirow{3}{*}{ Kochi } & \multirow{3}{*}{26} & Helminths & $19(73.08)$ & $(56.03,90.13)$ \\
\hline & & Protozoa & $5(19.23)$ & $(4.08,34.38)$ \\
\hline & & Total & $19(73.08)$ & $(56.03,90.13)$ \\
\hline \multirow{3}{*}{ Hermata Mentina } & \multirow{3}{*}{36} & Helminths & $28(77.78)$ & $(64.20,91.36)$ \\
\hline & & Protozoa & $13(36.1)$ & $(20.42,51.80)$ \\
\hline & & Total & $29(80.56)$ & $(67.62,93.48)$ \\
\hline \multirow{3}{*}{ Bocho Bore } & \multirow{3}{*}{72} & Helminths & $54(75.00)$ & $(65.00,85.00)$ \\
\hline & & Protozoa & $40(55.56)$ & $(44.08,67.03)$ \\
\hline & & Total & $61(84.72)$ & $(76.41,93.03)$ \\
\hline Total & 201 & Helminths and protozoa & $152(75.62)$ & $(69.69,81.57)$ \\
\hline
\end{tabular}

CI: confidence interval.

TABLE 2: Percentage of parasites isolated from the gut contents and external body surfaces of the populations of B. germanica in Jimma Town, southwestern Ethiopia, 2012.

\begin{tabular}{|c|c|c|c|}
\hline Body part examined & Parasite isolated & $n(\%)$ & $95 \% \mathrm{CI}$ \\
\hline \multirow{4}{*}{ External body } & Only helminths & $15(7.46)$ & $(3.83,11.10)$ \\
\hline & Only protozoa & $5(2.48)$ & $(0.33,4.64)$ \\
\hline & Both & $2(0.10)$ & $(0.00,2.37)$ \\
\hline & Total & $22(10.95)$ & $(6.63,15.26)$ \\
\hline \multirow{4}{*}{ Gut } & Only helminths & $87(43.28)$ & $(36.43,50.13)$ \\
\hline & Only protozoa & $55(27.36)$ & $(21.20,0.34)$ \\
\hline & Both & $10(4.98)$ & $(1.96,7.98)$ \\
\hline & Total & $152(75.62)$ & $(69.69,81.57)$ \\
\hline \multirow{4}{*}{ Total } & Only helminths & $81(40.30)$ & $(33.52,47.08)$ \\
\hline & Only protozoa & $10(4.98)$ & $(1.97,7.98)$ \\
\hline & Both & $61(30.35)$ & $(23.99,36.70)$ \\
\hline & Total & $152(75.62)$ & $(69.69,81.57)$ \\
\hline
\end{tabular}

CI: confidence interval.

specimens examined had been found to harbor at least one species of human intestinal parasites.

A similar high parasite carriage rate $(77.52 \%)$ had been reported from external body surfaces of cockroaches from Nigeria [8]. In contrast, no parasite species were isolated from cockroach specimens collected from residential areas; in Iran, however, in the same study, the percentage of cockroach specimens collected from public hospitals carrying intestinal parasites was low [3]. In Thailand, $54.1 \%$ of cockroach specimens collected from market places was reported to harbor parasite species [6]. Differences in the hygienic condition of the environments, including human excreta disposal, may account for the observed variation in the parasite carriage rate among different settings.
Overall, seven species of intestinal parasites were isolated from the cockroach specimens. The protozoan parasite species isolated were E. histolytica/dispar/moshkovskii, G. duodenalis, and B. coli. In a previous study, the potential role of cockroaches in the mechanical transmission of $E$. histolytica cysts had been reported [10]. Moreover, four species of intestinal helminthes, A. lumbricoides, T. trichiura, Taenia species, and an unidentified Strongyloides-like parasite, were isolated.

Several studies had previously reported that some of these parasite species and different species of bacteria and fungi were isolated from cockroaches [7, 8, 18]. Feeding starved roaches with microorganisms also resulted in the recovery of the microorganisms in the feces of the roaches $[19,20]$. 


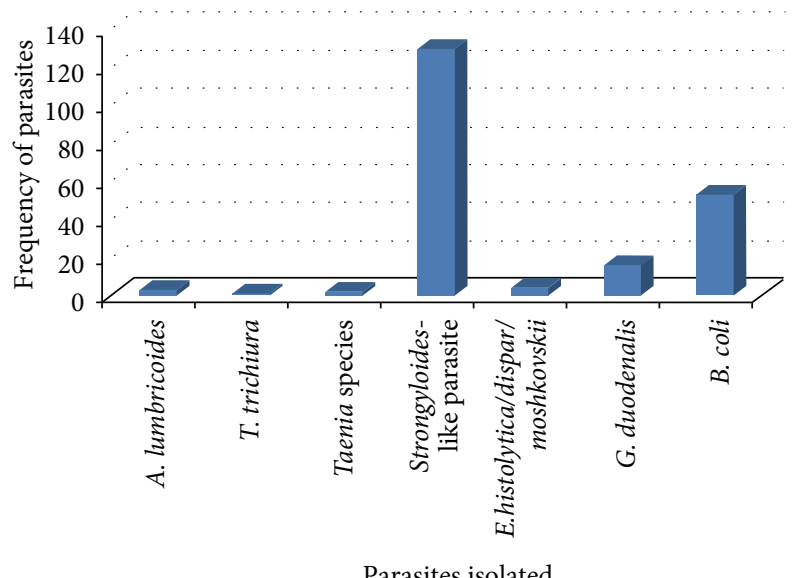

Figure 1: Percentage of parasite species isolated from populations of B. germanica in Jimma Town, southwestern Ethiopia, 2012.

No oocysts of the coccidian parasites (Cryptosporidium and Cyclospora species) had been isolated from cockroach specimens in contrast to previous reports $[6,9]$.

\section{Conclusions}

Intestinal parasite carriage rate of cockroaches in Jimma Town was high. In this study, many parasite species which are known to cause intestinal parasitosis in humans had been isolated mainly from the gut contents of the cockroach specimens. The finding of this study sheds light on the potential role of cockroaches in the mechanical transmission of human intestinal parasites.

\section{Conflict of Interests}

The authors declare that there is no conflict of interests regarding the publication of this paper.

\section{Acknowledgments}

The authors would like to acknowledge Jimma University for the financial support. They would also like to thank Jimma Town municipality and the kebele officials for allowing them to undertake the study. Finally, the authors acknowledge the households that participated in the study.

\section{References}

[1] A. Kumie, K. Genete, H. Worku, E. Kebede, and F. Ayele H Mulugeta, "The sanitary conditions of public food and drink establishments in the district town of Zeway, Southern Ethiopia," Ethiopian Journal of Health Development, vol. 16, no. 1, pp. 95-104, 2002.

[2] P. J. Gullan and P. S. Cranston, The Insects: An Outline of Entomology, Blackwell, Davis, Calif, USA, 2005.

[3] A. Salehzadeh, P. Tavacol, and H. Mahjub, "Bacterial, fungal and parasitic contamination of cockroaches in public hospitals of
Hamadan, Iran," Journal of Vector Borne Diseases, vol. 44, no. 2, pp. 105-110, 2007.

[4] M. A. Baumholtz, L. C. Parish, J. A. Witkowski, and W. B. Nutting, "The medical importance of cockroaches," International Journal of Dermatology, vol. 36, no. 2, pp. 90-96, 1997.

[5] N. Y. Al-bayati, A. S. Al-Ubaidi, and I. K. Al-Ubaidi, "Risks associated with cockroach Periplaneta americana as a transmitter of pathogen agents," Diyala Journal of Medicine, vol. 1, no. 1, pp. 91-97, 2011.

[6] P. Chamavit, P. Sahaisook, and N. Niamnuy, "The majority of cockroaches from the Samutprakarn province of Thailand are carriers of parasitic organisms," EXCLI Journal, vol. 10, pp. 218222, 2011.

[7] A. Kinfu and B. Erko, "Cockroaches as carriers of human intestinal parasites in two localities in Ethiopia," Transactions of the Royal Society of Tropical Medicine and Hygiene, vol. 102, no. 11, pp. 1143-1147, 2008.

[8] A. Y. Bala and H. Sule, "Vectorial potential of cockroaches in transmitting parasites of medical importance in Arkilla, Sokoto, Nigeria," Nigerian Journal of Basic and Applied Sciences, vol. 20, no. 2, pp. 111-115, 2012.

[9] G. T. El-Sherbini and E. T. El-Sherbini, "The role of cockroaches and flies in mechanical transmission of medical important parasites," Journal of Entomology and Nematology, vol. 3, no. 7, pp. 98-104, 2011.

[10] H.-H. Pai, Y. C. Ko, and E. R. Chen, "Cockroaches (Periplaneta americana and Blattella germanica) as potential mechanical disseminators of Entamoeba histolytica," Acta Tropica, vol. 87, no. 3, pp. 355-359, 2003.

[11] R. Fotedar, U. Banerjee Shriniwas, and A. Verma, "Cockroaches (Blattella germanica) as carriers of microorganisms of medical importance in hospitals," Epidemiology and Infection, vol. 107, no. 1, pp. 181-187, 1991.

[12] D. L. Rosenstreich, P. Eggleston, M. Kattan et al., "The role of cockroach allergy and exposure to cockroach allergen in causing morbidity among inner-city children with asthma," The New England Journal of Medicine, vol. 336, no. 19, pp. 1356-1363, 1997.

[13] S. B. Sarpong, R. G. Hamilton, P. A. Eggleston, and N. F. Adkinson Jr., "Socioeconomic status and race as risk factors for cockroach allergen exposure and sensitization in children with asthma," Journal of Allergy and Clinical Immunology, vol. 97, no. 6, pp. 1393-1401, 1996.

[14] A. Mengistu, S. Gebre-Selassie, and T. Kassa, "Prevalence of intestinal parasitic infections among urban dwellers in southwest Ethiopia," Ethiopian Journal of Health Development, vol. 21, no. 1, pp. 12-17, 2007.

[15] W. Legesse S Gebre-Selassie, "Sanitary survey of residential areas using Ascaris lumbricoides ova as indicators of environmental hygiene, Jimma, Ethiopia," Ethiopian Journal of Health Development, vol. 21, no. 1, pp. 18-24, 2007.

[16] H. H. Ross, Textbook of Entomology, Wiley \& Sons, New York, NY, USA, 3rd edition, 1965.

[17] M. Cheesbrough, District Laboratory Practice in Tropical Countries, Part I, Cambridge University Press, 2009.

[18] P. Saichua, K. Pinmai, S. Somrithipol, and S. Tor-Udom, "Isolation of medically important fungi from cockroaches trapped at Thammasat Chalermprakiat Hospital," Thammasat Medical Journal, vol. 8, no. 3, pp. 345-351, 2008.

[19] B. W. Allen, "Excretion of viable tubercle bacilli by Blatta orientalis (the oriental cockroach) following ingestion of heatfixed sputum smears: a laboratory investigation," Transactions 
of the Royal Society of Tropical Medicine and Hygiene, vol. 81, no. 1, pp. 98-99, 1987.

[20] E. Tachbele, W. Erku, T. Gebre-Michael, and M. Ashenaf, "Cockroach-associated foodborne bacterial pathogens from some hospitals and restaurants in Addis Ababa, Ethiopia: distribution and antibiograms," Journal of Rural and Tropical Public Health, vol. 5, pp. 34-41, 2006. 

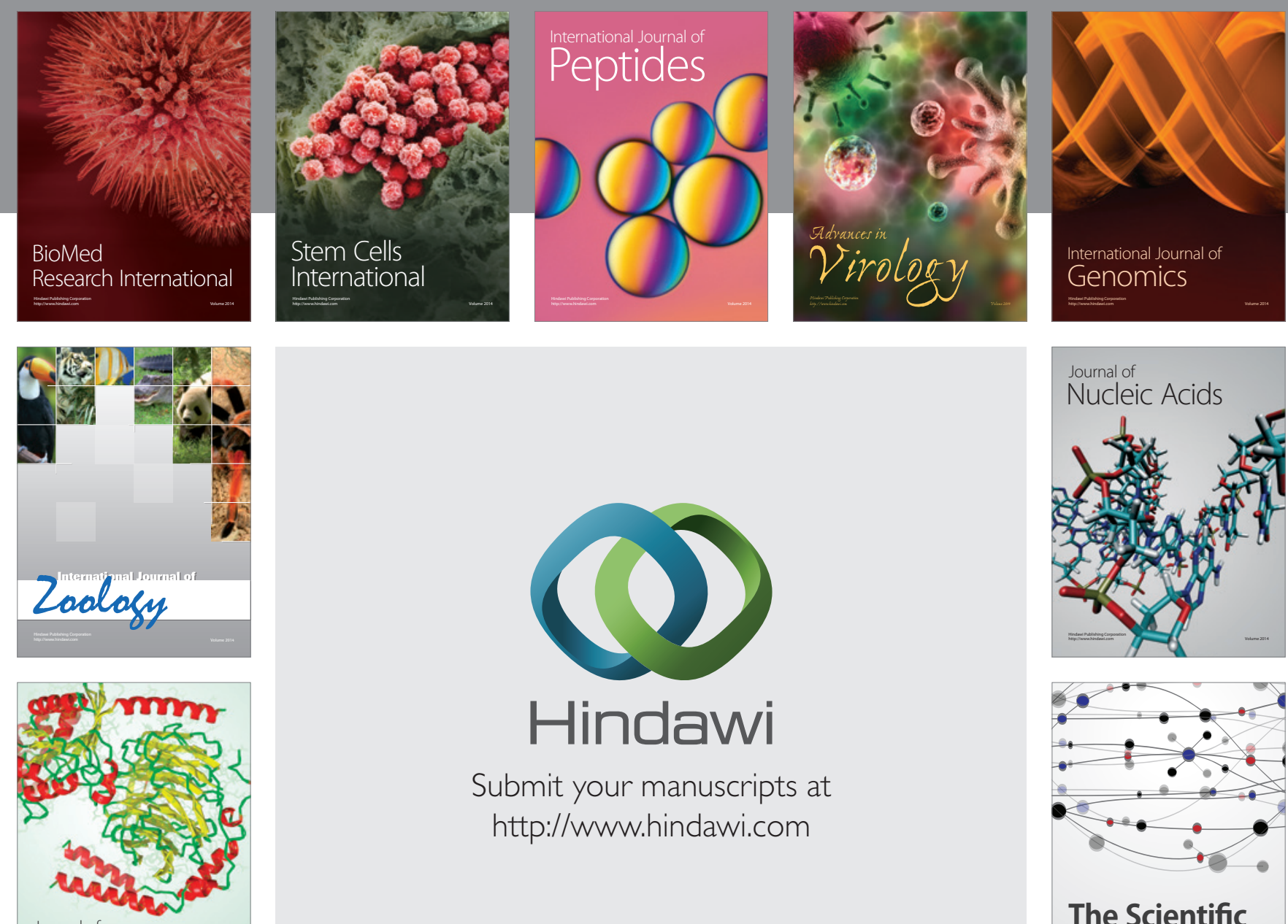

Submit your manuscripts at

http://www.hindawi.com

Journal of
Signal Transduction
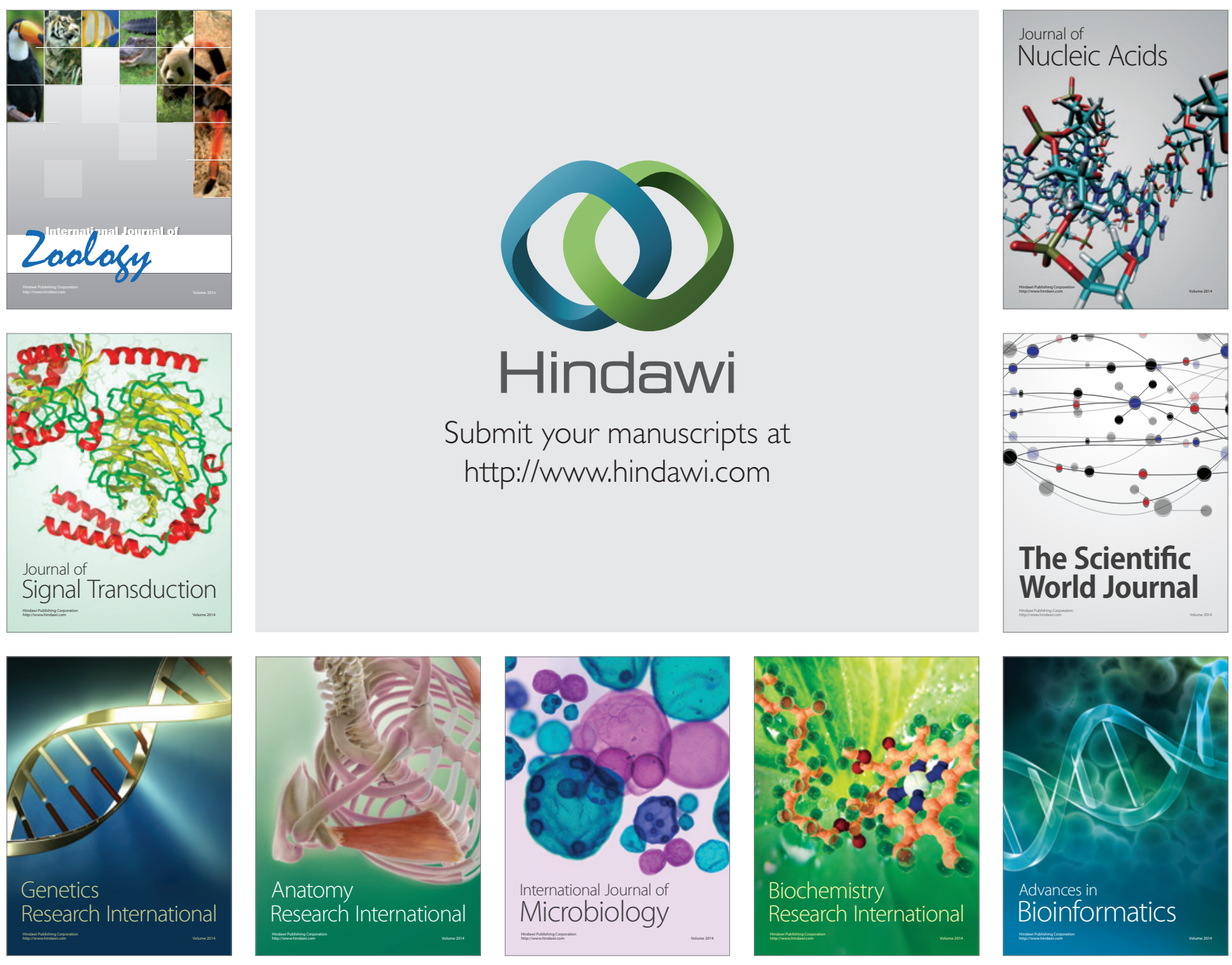

The Scientific World Journal
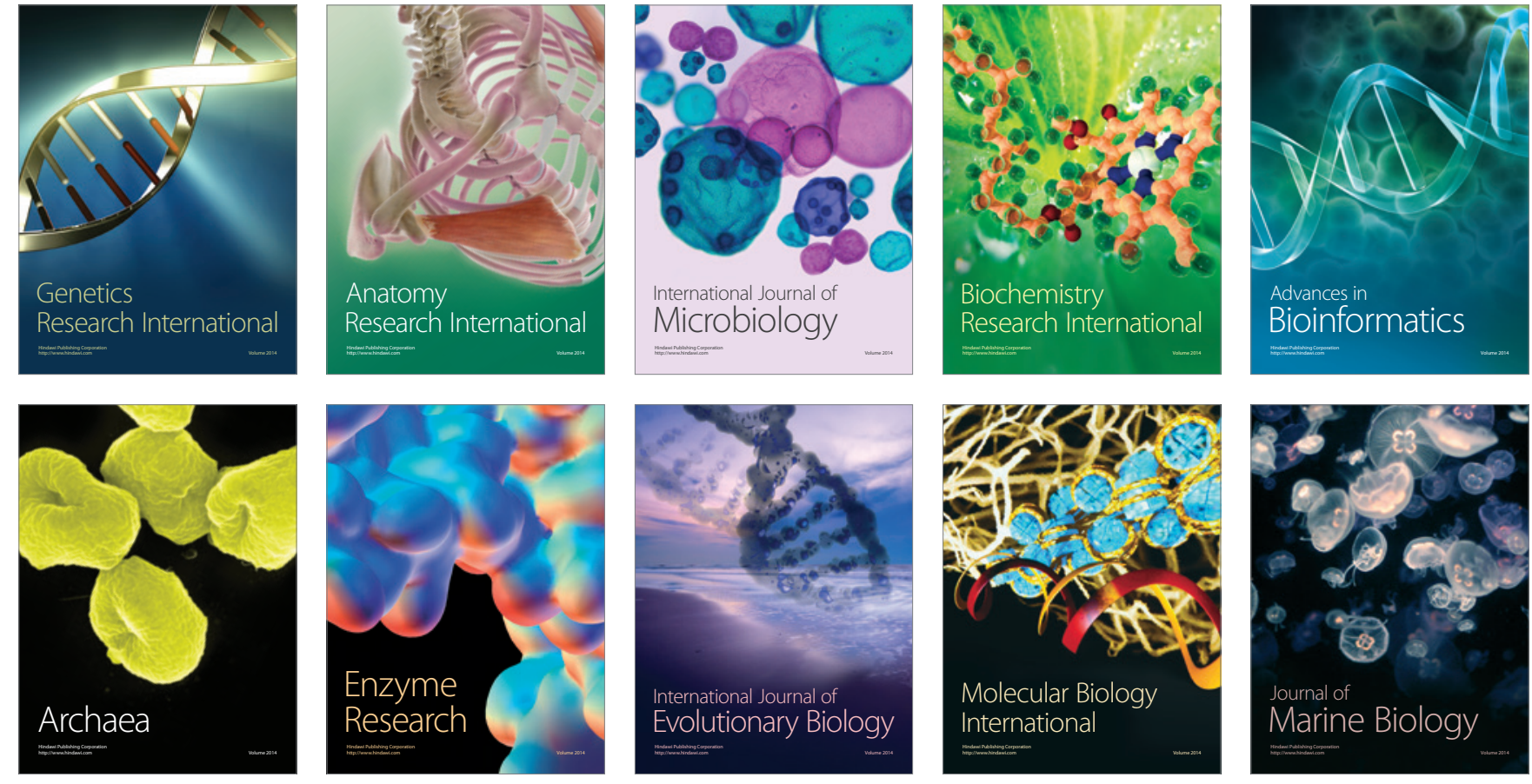